\title{
Molecular characterization and expression analysis of the NLR family CARD containing five transcripts in the pig
}

\author{
Q.Y. Yang, T. Chen, Y.B. Chen, D.L. Lan \\ College of Life Science and Technology, Southwest University for Nationalities, \\ Chengdu, Sichuan, 610041, China
}

\begin{abstract}
The NOD-like receptor (NLR) family caspase recruitment domain-containing 5 (NLRC5) is one of the newly discovered and largest NLR family members. The NLRC5 has recently received extensive attention because of its important role in regulating innate and adaptive immune responses. The NLRC5 in many vertebrates, such as humans, mice, cattle, and horses, has already been proven and studied. However, the NLRC5 gene characteristics of pigs remain unclear. Thus, we completely cloned the NLRC5 cDNA sequence of the pig using the rapid amplification of cDNA ends(RACE) technology. A characteristic and tissue expression analysis was also conducted on the pig sequence. The sequence analysis showed that the complete cDNA sequence of the NLRC5 of the pig is $6638 \mathrm{bp}$, and the open reading frame is 5538 bp which encoded 1846 amino acids. The protein prediction analysis indicates that the overall performance of the NLRC5 protein of the pig is hydrophilic and possesses a typical nucleotide binding and oligomerization domain(NBD) and 20 leucine-rich repeats(LRRs). The homology analysis result indicates that the NLRC5 transcript in pigs is highly homologous to cattle, sheep, macaques, and humans, and accounts for around $80 \%$. The genetic evolutionary tree analysis shows that the NLRC5 transcript in pigs has the closest evolutionary relationship with cattle and sheep. Further tissue expression analysis shows that immune organ systems (e.g., lymph node and spleen) and mucosa organs (e.g., intestinal lymph node, stomach, and lungs) possess high expressions with NLRC5 mRNA. The result of this study indicates that the NLRC5 transcript in pigs is relatively conservative among mammals and may play a vital role in immune reaction, which provides a basis for further studies on the NLRC5 function in the pig immune system and the role in comparative immunity.
\end{abstract}

Key words: NLRC5 transcript, pig, gene cloning, sequence analysis, expression distribution 


\section{Introduction}

NOD-like receptors (NLRs) are one of the known four pattern recognition receptor families that are located within the cytoplasm. NLRs mainly recognize the pathogenic microorganism and danger signal in the cytoplasm (Kanneganti et al. 2007, Kumar et al. 2009). Many members in this family play critical roles in immune regulation. The NOD-like receptor (NLR) family caspase recruitment domain (CARD) domain-containing 5 (NLRC5) is one of the newly discovered NLR family members, and has by for the highest molecular weight among the known family members by far. The NLRC5 has received extensive attention in recent years as a new innate immune regulation molecule (Meissner et al. 2012, Zhao and Shao 2012, Neerincx et al. 2013). Among the many cell types of humans and mice, the NLRC5 has been proven to have a remarkable regulatory effect on producing a pathway to type I interferon(IFN), which plays a significant role in antiviral and antibacterial innate immune processes. The NLRC5 not only upregulates the transcription and expression of the classical major histocompatibility complex (MHC) type I molecule gene human leukocyte antigen (HLA-A, B, C) and non-classical MHC type I molecule gene HLA-E (Meissner et al. 2010, Meissner et al. 2012, Yao et al. 2012, Neerincx et al. 2014), but also plays a key role in inflammasome formation (Benko et al. 2010, Davis et al. 2011). Providing an effective immune target for the prevention and treatment of microbial infection diseases is possible in terms of the important role of the NLRC5 protein in the innate immune process.

The NLRC5 receptor exists in many vertebrates, such as humans, apes, mice, cattle, and horses (Meissner et al. 2012, Zhao and Shao 2012, Motyan et al. 2013). However, studies regarding the NLRC5 gene in pigs have not yet been reported. The pig is a more superior experimental animal model than mice $(\mathrm{Ku}-$ dlicka et al. 2015). Therefore, studying the relevant effects of the NLRC5 gene in the pig possesses a certain reference meaning for further exploration of its effects in humans. Moreover, major infectious bacterial and viral diseases are a threat to the healthy development of the pig breeding industry, thereby leading to huge economic losses in China and worldwide. Therefore, an in-depth study on the NLRC5 gene in the pig is of great significance to further prevent and control porcine infectious diseases effectively. This study is the first to clone the NLRC5 transcript in the pig and conducts a bioinformatics analysis on the obtained sequences. The relevant tissue expression distribution, which provides a theoretical foundation for the subsequent study of NLRC5 effects in pigs and its role in the innate immune process, is also studied.

\section{Materials and Methods}

\section{Sample collection}

Three male and three female piglets (4 months old) were randomly selected. Several fresh tissue samples (e.g., small intestine, spleen, lung, and stomach) were collected from slaughtered pigs and immediately frozen in liquid nitrogen until future use. The animal care and use committee approval in this study was not required because the samples were obtained opportunistically from government-inspected slaughter facilities.

\section{RNA extraction and cDNA synthesis}

Total RNA was isolated from the tissue sample (100 mg) using TRIzol Reagent (Life Technology, USA) according to the instructions and treated with DNase I (Qiagen, Germany) before analysis. RNA quality was evaluated based on the A260/280 ratio (1.6-2.0). RNA integrity was tested using $1 \%$ agarose gel electrophoresis. cDNA was synthesized using the SuperScript ${ }^{\circledR}$ III First-strand Synthesis System (Life Technology, USA) as follows. Total RNA ( $6 \mu \mathrm{l}), 50$ $\mu \mathrm{m}$ oligo $\left(\mathrm{dT}_{20} ; 1 \mu \mathrm{l}\right)$, and $10 \mathrm{mM}$ dNTP mix $(1 \mu \mathrm{l})$ were added to a tube with diethylpyrocarbonate-treated $\mathrm{H}_{2} \mathrm{O}$ to obtain a total volume of $10 \mu \mathrm{l}$. The tube was incubated at $65^{\circ} \mathrm{C}$ for $5 \mathrm{~min}$ and then cooled on ice. A mixture of $2 \mu \mathrm{l}$ of $10 \times \mathrm{RT}$ buffer, $4 \mu \mathrm{l}$ of 25 $\mathrm{mM} \mathrm{MgCl}, 2 \mu \mathrm{l}$ of $0.1 \mathrm{mM}$ DTT, $1 \mu \mathrm{l}$ of RNase

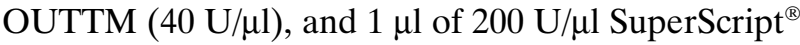
III RT was added to the tube to achieve a total volume of $20 \mu \mathrm{l}$. The tube was incubated at $50^{\circ} \mathrm{C}$ to react for $50 \mathrm{~min}$ and $85^{\circ} \mathrm{C}$ for $5 \mathrm{~min}$. It was then cooled on ice, and $1 \mu \mathrm{l}$ of RNase $\mathrm{H}$ was added to blend evenly. The tube was incubated at $37^{\circ} \mathrm{C}$ to react for $20 \mathrm{~min}$, and cDNA was stored at $-20^{\circ} \mathrm{C}$.

\section{cDNA cloning}

The primer was designed with reference to the NLRC5 gene of humans, mice, and other mammals to segment and amplify the NLRC5 gene in pigs (Table 1). TaKaRa LA Taq $(0.5 \mu \mathrm{l}), 10 \times$ LA PCR buffer II $\left(\mathrm{Mg}^{2+}\right.$ free; $\left.5 \mu \mathrm{l}\right), \mathrm{MgCl}_{2}(25 \mathrm{mM} ; 5 \mu \mathrm{l})$, dNTP mixture (2.5 mM each; $8 \mu \mathrm{l})$, cDNA template $(1 \mu \mathrm{l})$, forward and reverse primers $(1 \mu \mathrm{l}$ each $)$, and $\mathrm{ddH}_{2} \mathrm{O}(28.5 \mu \mathrm{l})$ were added to the $50 \mu \mathrm{l} \mathrm{PCR}$ reaction system. The PCR reaction condition was as follows: $94^{\circ} \mathrm{C}$ for $5 \mathrm{~min}$ for 35 cycles $\left(94^{\circ} \mathrm{C}\right.$ for $30 \mathrm{~s}, 58^{\circ} \mathrm{C}$ or $60^{\circ} \mathrm{C}$ for $30 \mathrm{~s}$, and $72^{\circ} \mathrm{C}$ for $60-90 \mathrm{~s}$ ) and $72^{\circ} \mathrm{C}$ for $10 \mathrm{~min}$. The optimal annealing time was obtained according to the differ- 
Table 1. Primer sequences used in cDNA cloning.

\begin{tabular}{|c|c|c|c|}
\hline Primer name & Primer sequence $\left(5^{\prime} \rightarrow 3^{\prime}\right)$ & Amplified fragment(bp) & Annealing $\operatorname{Tm}(?)$ \\
\hline $\begin{array}{l}1 \mathrm{~S} \\
1 \mathrm{~A}\end{array}$ & $\begin{array}{l}\text { GGACCCCATTAGTCGCCAC } \\
\text { CAGCCACGCAGTGACATAGC }\end{array}$ & \multirow[t]{2}{*}{1764} & \multirow[t]{2}{*}{58} \\
\hline $1 \mathrm{~A}$ & CAGCCACGCAGTGACATAGC & & \\
\hline $2 S$ & TGGACAGAGACACACTTGCCC & \multirow[t]{2}{*}{1081} & \multirow[t]{2}{*}{58} \\
\hline $2 \mathrm{~A}$ & GCCACCAGTTGACAGCCTTC & & \\
\hline $3 \mathrm{~S}$ & TGTCTCCGTGTCAACTCTCCTC & \multirow{2}{*}{828} & \multirow{2}{*}{58} \\
\hline $3 \mathrm{~A}$ & CCTCTGCTGTCACCGCTCA & & \\
\hline $4 \mathrm{~S}$ & ACGGTTTGTCCCTGGATGCT & \multirow{2}{*}{1189} & \multirow{2}{*}{60} \\
\hline $4 \mathrm{~A}$ & GCCACGGCTTCTGGGTTCT & & \\
\hline $5 \mathrm{~S}$ & AGGCAACGTCACTGAAATAAGC & \multirow{2}{*}{763} & \multirow{2}{*}{58} \\
\hline $5 \mathrm{~A}$ & CACAGGCGAATGACTTGGAT & & \\
\hline $6 \mathrm{~S}$ & TCAACTTGGCCGAGAACAGC & \multirow{2}{*}{429} & \multirow{2}{*}{58} \\
\hline $6 \mathrm{~A}$ & AGGGGACCTGTGGCTGATG & & \\
\hline $7 \mathrm{~S}$ & GACAACCAGACTGCCAAGCC & \multirow{2}{*}{1253} & \multirow{2}{*}{60} \\
\hline 7A & CTTGGGCCTTCTTGGAAACA & & \\
\hline
\end{tabular}

Table 2. RACE primer sequences.

\begin{tabular}{cc}
\hline Primer name & Primer sequence $\left(5^{\prime} \rightarrow 3^{\prime}\right)$ \\
\hline 5' race GSP primer 1 & GATGGGCGGGATGTAGGTTCGG \\
5' race GSP primer 2 & GCCAGTTCTCGCTGCTGCTTCC \\
3' race GSP primer 1 & GGAACTGGCTCACCCCTCCCGTA \\
3' race GSP primer 2 & CGCTGGACCCGGCCACTACCTCA \\
\hline
\end{tabular}

Table 3. Real-time PCR primer sequences.

\begin{tabular}{cc}
\hline Primer name & Primer sequence $\left(5^{\prime} \rightarrow 3^{\prime}\right)$ \\
\hline QNLRC5-S & AACTTGGCCGAGAACAGC \\
QNLRC5-A & TTCCACAGGCGAATGACTT \\
Qactin-S & GTCATCACCATCGGCAACG \\
Qactin-A & AACAGTCCGCCTAGAAGCATT \\
\hline
\end{tabular}

ent sizes of the amplified fragments. The PCR outcomes were analyzed with $1 \%$ agarose gel electrophoresis. The amplified target fragment was linked with cloning vector PMD-19 and transformed into DH5a competent cells. The bacteria liquid PCR was correctly tested and sent to Life Technology (Shanghai, China) for sequencing.

\section{cDNA 5' and 3 ' terminal sequence cloning}

The 5' and 3' rapid amplification of cDNA end (RACE) primers (Table 2) used to clone the 5' and 3' terminal sequences using the SMARTer RACE kit (Clontech, Japan) were designed with reference to the NLRC5 fragment sequence of the pig amplified in the previous step. First, the isolated RNA was reverse transcribed to the first-chain cDNA using the SMARTer II oligonucleotide and CDS primers in the kit. The synthesized first-chain cDNA was then used as the template to amplify the 5' and 3' terminal sequences by two rounds of nested PCR with the designed race and universe UPM primers in the kit. The $50 \mu \mathrm{l}$ PCR reaction system contained $5 \mu \mathrm{l}$ of 10× Advantage 2 PCR buffer, $1 \mu$ l of dNTP mix ( $10 \mathrm{mmol} \mathrm{L}), 1 \mu \mathrm{l}$ of $50 \times$ Advantage 2 polymerase mix, $2.5 \mu \mathrm{l}$ of temple cDNA, $1 \mu \mathrm{l}$ of 5 ' or 3' race GSP primer, $5 \mu$ l of UPM primer, and $34.5 \mu$ l of dd $\mathrm{H}_{2} \mathrm{O}$. The PCR reaction procedure was performed using the nested PCR program as follows: five cycles $\left(94^{\circ} \mathrm{C}\right.$ for $30 \mathrm{~s}$ and $72^{\circ} \mathrm{C}$ for $\left.3 \mathrm{~min}\right)$ were first circulated. The reaction condition $\left(94^{\circ} \mathrm{C}\right.$ for $30 \mathrm{~s}, 68^{\circ} \mathrm{C}$ for $30 \mathrm{~s}$, and $72^{\circ} \mathrm{C}$ for $3 \mathrm{~min}$ ) was then run for 35 cycles. The PCR outcome was taken as the template, and the second 5' or 3' race GSP primer made the second cycle of PCR, with the reaction conditions of $94^{\circ} \mathrm{C}$ for $30 \mathrm{~s}, 68^{\circ} \mathrm{C}$ for $30 \mathrm{~s}$, and $72^{\circ} \mathrm{C}$ for $3 \mathrm{~min}$ for 20 cycles. The outcomes of the two PCR cycles were analyzed with $1 \%$ agarose gel electrophoresis. The amplified target fragment was recycled and linked with cloning vector PMD-19. The fragment was then transformed into DH5a competent cells. The bacteria liquid PCR was correctly tested and sent to Life Technology (Shanghai, China) for sequencing. 


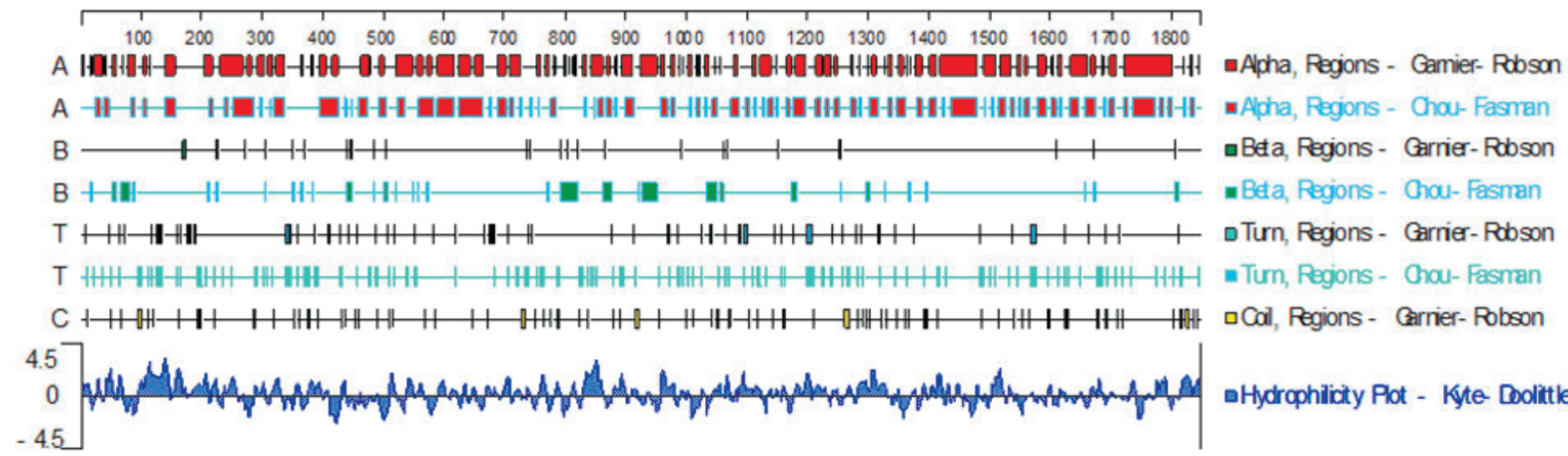

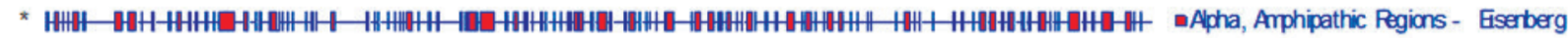

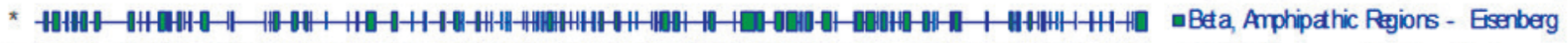

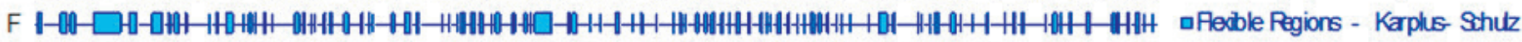
1.7
0

1.7

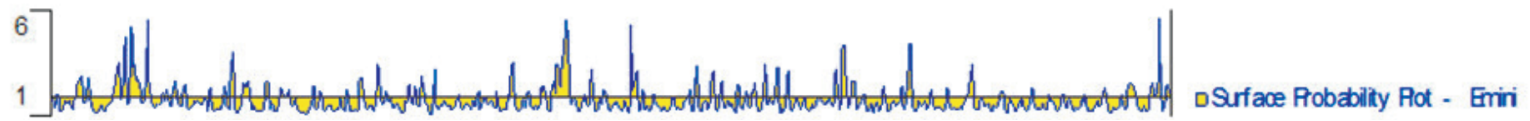

Fig. 1. Predicted results of hydrophilicity, flexibility, surface probability and antigenicity of NLRC5 gene in the pig.

\section{Bioinformatics analysis of the NLRC5 cDNA}

The complete cDNA sequence of the pig NLRC5 was obtained by assembling the amplified fragment sequence. The open reading frame and amino acid sequence of the NLRC5 were predicted on the NCBI online ORF finder software. Further sequence characteristics were analyzed with DNA Star and MEGA5.0 software, as well as SMART online software.

\section{Tissue expression analysis of pig NLRC5 mRNA by real-time PCR}

The pig NLRC5 mRNA in the tissues was quantitatively analyzed by real-time PCR using $\beta$-actin as the reference gene. Table 3 shows the designed real-time PCR primer. The $20 \mu \mathrm{l}$ real-time PCR reaction contained the following: $10 \mu \mathrm{l}$ of SYBR Premix Ex $T a q^{\mathrm{TM}}$ II (Takara, Japan), $2 \mu$ of cDNA template, $0.8 \mu \mathrm{l}$ each of the forward and reverse primers, and $6.4 \mu \mathrm{l}$ of $\mathrm{ddH}_{2} \mathrm{O}$. The Bio-Rad CFX-96 real-time PCR amplifier (USA) was used for the fluorescence quantitative analysis. The optimum reaction procedure was $95^{\circ} \mathrm{C}$ initial denaturation for $30 \mathrm{~s}, 95^{\circ} \mathrm{C}$ denaturation for $5 \mathrm{~s}, 55^{\circ} \mathrm{C}$ annealing for $30 \mathrm{~s}$, and $72^{\circ} \mathrm{C}$ extension for $20 \mathrm{~s}$ for 39 cycles. A solubility curve was generated. In addition, $\mathrm{dd}_{2} \mathrm{O}$ was used as the negative template control. The experiments were repeated three thrices for each tissue. The relatively quantitative $2^{-\Delta \Delta C T}$ was adopted to conduct the data analysis. The muscle expression was taken as the basis of reference to calculate the relative expression of the other tissues.

\section{Results}

\section{cDNA sequence cloning of the pig NLRC5 gene}

The full-length cDNA sequence of the pig NLRC5 was obtained by assembling the amplified fragment sequence by RT-PCR and race technology (GenBank number: KC514136). The complete cDNA sequence of the pig NLRC5 is $6638 \mathrm{bp}$. The open reading frame of the gene is $5538 \mathrm{bp}$ and encoded a total of 1846 amino acids.

\section{Prediction of the hydrophilicity, hydrophobicity, flexibility, and antigenicity of the pig NLRC5 protein}

The hydrophilicity, hydrophobicity, flexibility, and antigenicity of the NLRC5 mRNA-coding products were analyzed using DNA star software. The hydrophilic residues of the pig NLRC5 protein were more than the hydrophobic residues (Figure 1). Therefore, the overall performance of the pig NLRC5 protein was hydrophilic. In addition, a relatively large antigen epitope domain, within which the 5' terminal and central domains were concentrated, was found (Fig. 1). This domain can be inferred as the enrichment area of the antigen site. 


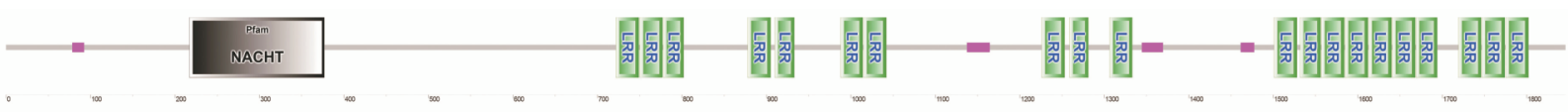

Fig. 2. Protein domain prediction of NLRC5 gene.

\begin{tabular}{|c|c|c|c|c|c|c|c|c|c|c|c|c|c|c|c|}
\hline \multicolumn{15}{|c|}{ Percent identity } & \multirow[b]{3}{*}{ Homo sapiens } \\
\hline & 1 & 2 & 3 & 4 & 5 & 6 & 7 & 8 & 9 & 10 & 11 & 12 & 13 & & \\
\hline 1 & & 75.0 & 81.7 & 74.0 & 78.2 & 43.2 & 78.2 & 81.4 & 95.9 & 78.9 & 79.0 & 50.2 & 97.4 & 1 & \\
\hline 2 & 31.0 & & 76.8 & 72.5 & 71.1 & 41.9 & 71.3 & 75.3 & 77.1 & 74.2 & 72.1 & 50.1 & 72.6 & 2 & Oryctolagus cuniculus \\
\hline 3 & 21.4 & 28.2 & & 72.8 & 80.9 & 43.8 & 80.9 & 82.8 & 81.6 & 83.0 & 82.8 & 50.2 & 79.5 & 3 & Equus caballus \\
\hline 4 & 32.7 & 35.2 & 34.6 & & 71.6 & 43.6 & 71.8 & 72.6 & 74.2 & 72.8 & 73.1 & 51.6 & 72.7 & 4 & Mus musculus \\
\hline 5 & 26.3 & 37.1 & 22.3 & 36.7 & & 42.6 & 95.1 & 80.5 & 80.1 & 83.3 & 79.0 & 49.6 & 75.5 & 5 & Ovis aries \\
\hline 6 & 109.4 & 115.6 & 107.1 & 107.3 & 112.2 & & 42.5 & 45.5 & 44.5 & 42.8 & 43.2 & 45.3 & 42.9 & 6 & Ictalurus punctatus \\
\hline 7 & 26.4 & 36.7 & 22.3 & 36.4 & 5.1 & 112.8 & & 80.8 & 80.1 & 83.6 & 78.1 & 49.9 & 75.7 & 7 & Bos taurus \\
\hline 8 & 21.9 & 30.5 & 19.8 & 35.0 & 22.9 & 100.0 & 22.6 & & 81.3 & 82.9 & 86.8 & 52.4 & 78.6 & 8 & Canis lupus \\
\hline 9 & 4.3 & 27.9 & 21.5 & 32.5 & 23.6 & 103.9 & 23.6 & 21.1 & & 80.6 & 81.2 & 52.5 & 95.1 & 9 & Macaca mulatta \\
\hline 10 & 25.3 & 32.1 & 19.5 & 34.6 & 19.1 & 111.5 & 18.8 & 19.7 & 22.9 & & 81.8 & 50.1 & 77.5 & 10 & Sus scrofa \\
\hline 11 & 25.1 & 35.2 & 19.8 & 34.1 & 25.1 & 109.6 & 26.4 & 14.8 & 22.1 & 21.2 & & 49.3 & 76.5 & 11 & Felis catus \\
\hline 12 & 84.0 & 83.7 & 78.1 & 79.8 & 85.6 & 100.7 & 84.7 & 77.2 & 77.1 & 84.4 & 86.5 & & 49.0 & 12 & Gallus gallus \\
\hline 13 & 2.6 & 34.6 & 24.3 & 34.9 & 30.2 & 110.4 & 30.0 & 25.8 & 5.1 & 27.3 & 28.8 & 87.7 & & 13 & Pan troglodytes \\
\hline & 1 & 2 & 3 & 4 & 5 & 6 & 7 & 8 & 9 & 10 & 11 & 12 & 13 & & \\
\hline
\end{tabular}

Fig. 3. Alignment of NLRC5 gene sequences.

\section{Structural domain analysis of the pig NLRC5 protein}

The structural domain of the encoding products of the pig NLRC5 was analyzed using SMART online software. Figure 2 shows the result. The pig NLRC5 matched the NLR family's basic structure, with the central segment being the NBD domain and fragment $\mathrm{C}$ possessing 20 leucine-rich repeats (LRRs).

\section{Homology analysis of the NLRC5 transcript}

Figure 3 shows the homology analysis result. Compared with the other 12 species, the highest homology with the pig NLRC5 was the NLRC5 transcript sequence of cattle and sheep (i.e., $83.6 \%$ and $83.3 \%$, respectively). The lowest homology, which accounted for $42.8 \%$ and $50.1 \%$, respectively, was found in the channel catfish and chicken. All the homologies of the NLRC5 transcript in the pig with the human, rabbit, horse, wolf, cat, macaque, and chimpanzee reached around $80 \%$. The result showed that the homology of the NLRC5 transcript in the pig and humans was $78.9 \%$, which was higher than that of human and mice $(74.0 \%)$. This result indicates that pig NLRC5 is relatively conservative in the long evolution, especially among mammals.

\section{Genetic evolutionary tree of the NLRC5 transcript}

The bootstrap-verified systematic genetic evolutionary tree for the NLRC5 transcript sequences of 13 species was constructed using the neighbor-joining method of MEGA5.0 software. The tree shown in Fig. 4 indicates that the genetic relations of the pig NLRC5 transcript with cattle and sheep were the closest ones, together with the horse, cat, macaque, human, chimpanzee, rabbit, and mouse forming a branch of mammals, and the chicken and duck forming another branch, which was relatively distant in genetic relation with the pig. The channel catfish formed the farthest genetic relation branch.

\section{Fluorescence specificity test}

Figure 5 shows the melting curves of the NLRC5 and the $\beta$-actin gene. The peaks of specificity appeared when the melting temperature of the NLRC5 reached $T_{m}=87.5^{\circ} \mathrm{C}$, and $\beta$-actin reached $T_{m}$ $=86.5^{\circ} \mathrm{C}$. These results indicate that the specificity of the primer performed well. Further sequencing results proved the correctness of the amplified fragment sequence. The standard curve showed that the correlation coefficient between NLRC5 and $\beta$-actin was 


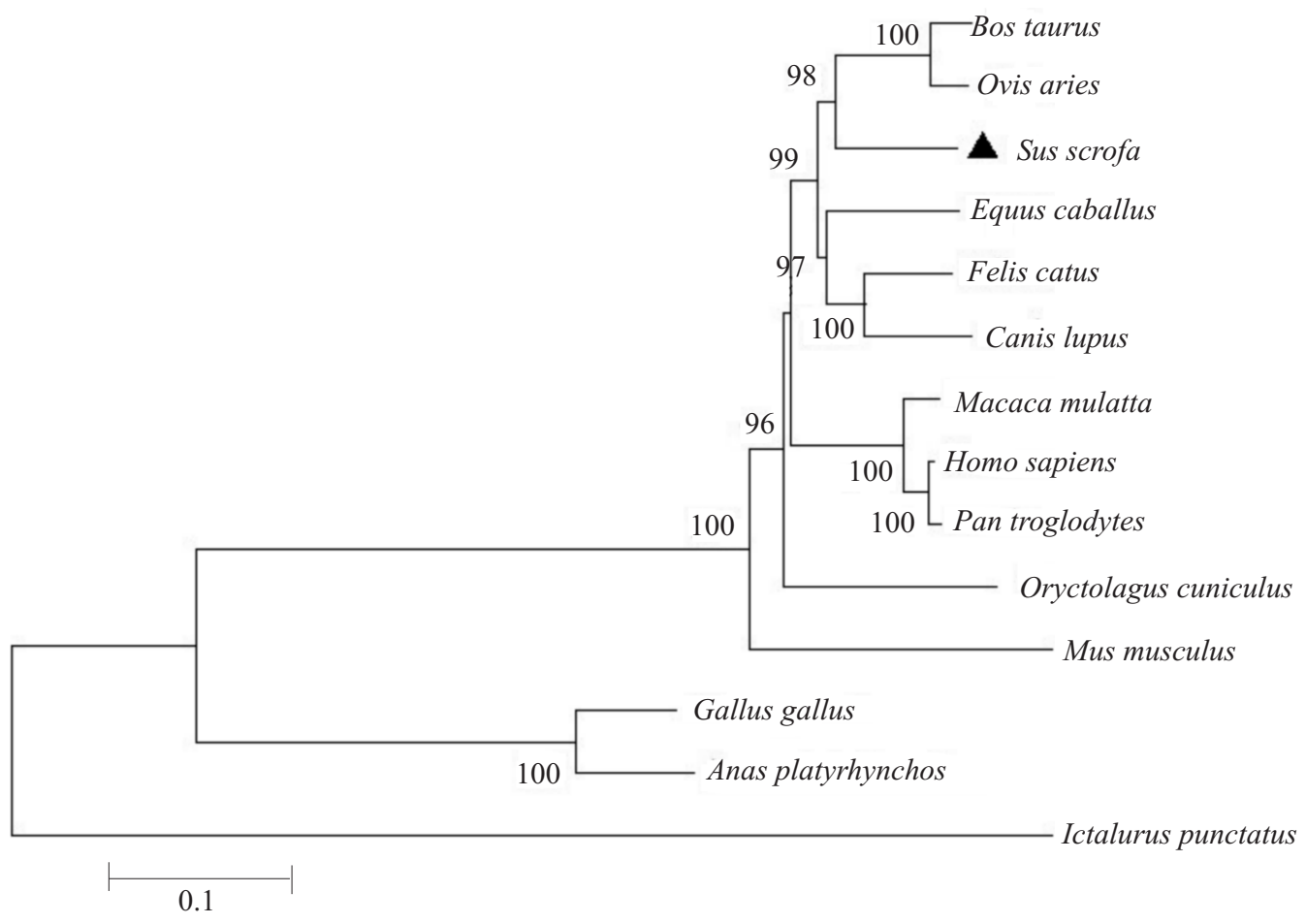

Fig. 4. Phylogenetic tree of NLRC5 gene sequences.

A

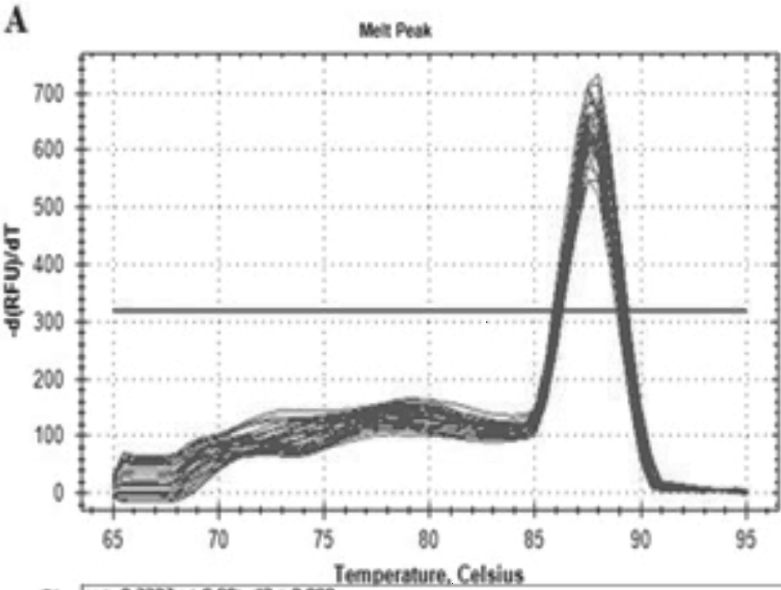

C

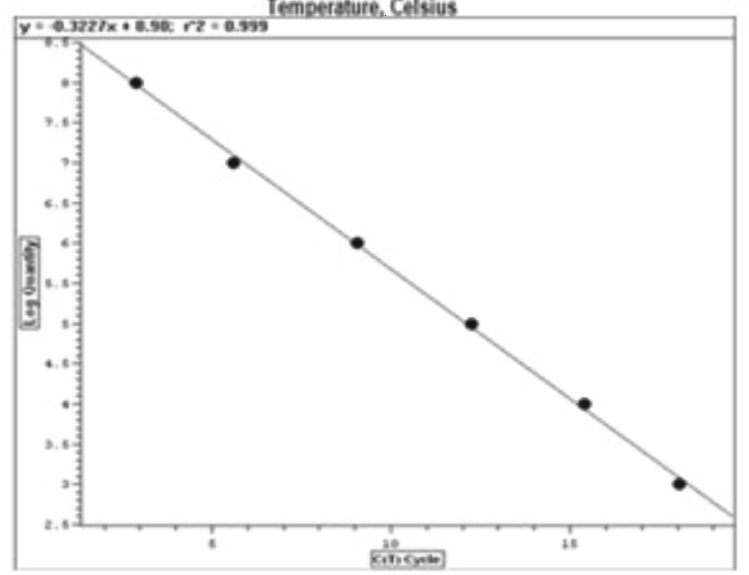

B
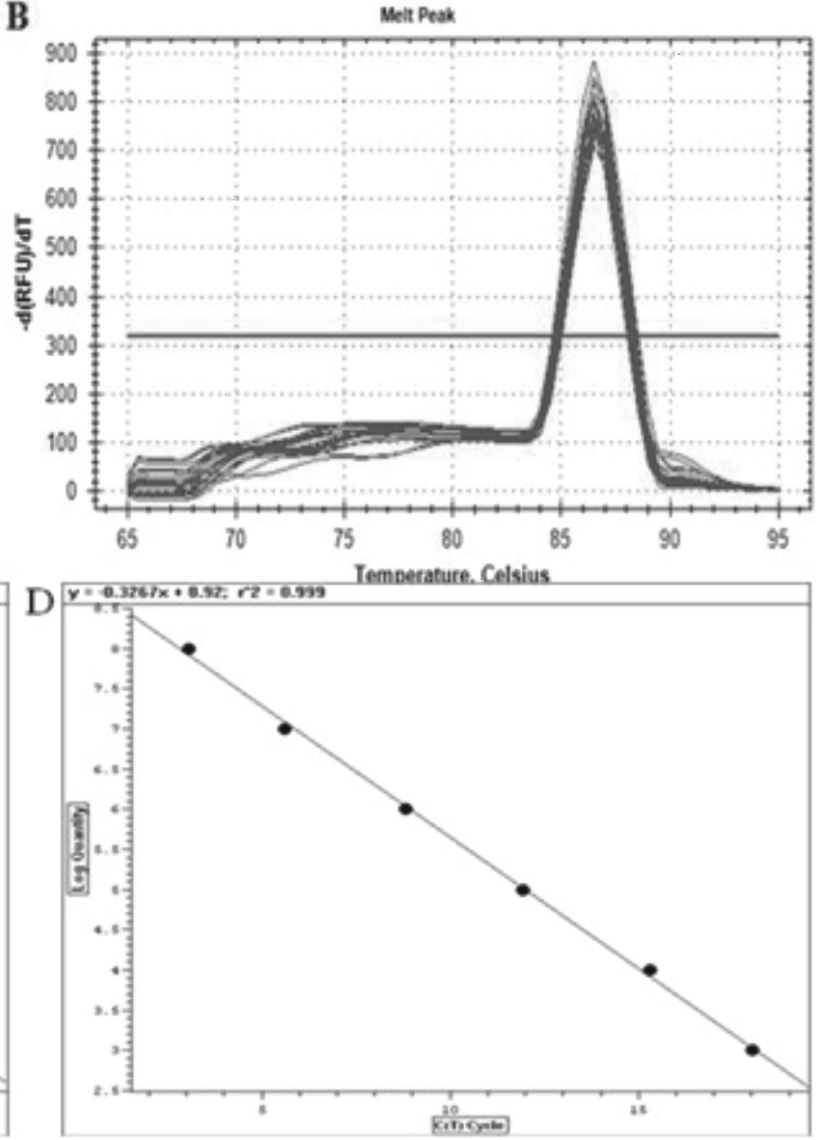

Fig 5. Real-time PCR melting curves and standard curve of NLRC5and f-actin gene. 


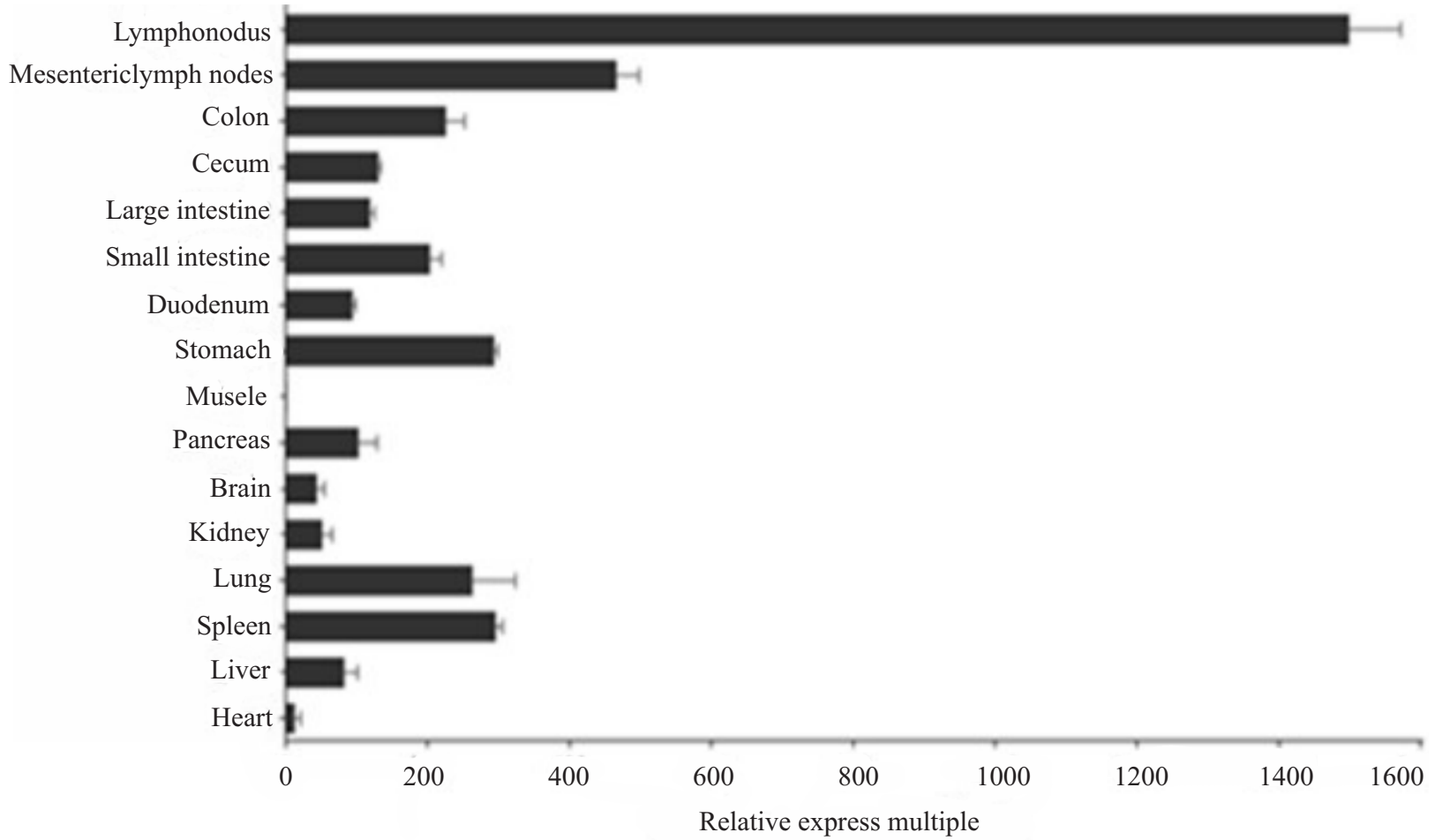

Fig. 6. Real-time PCR expression analysis of NLRC5 gene in different tissues of pig.

greater than 0.99 , which indicated a good linear relationship between the $\mathrm{Ct}$ value and the template concentration. The amplification efficiency between NLRC5 and the $\beta$-actin gene was basically the same.

\section{NLRC5 mRNA expression in different pig tissues}

The NLRC5 mRNA expression in different pig tissues was detected with real-time PCR technology. The muscle expression was taken as the basis of reference to calculate the relative expression of other tissues using the relatively quantitative $2^{-\Delta \Delta C T}$ method. Figure 6 shows the expression histogram, from which we can determine that the NLRC5 mRNA was of highest expression in the lymph node, lowest in the muscle, and had a high expression in the intestinal lymph node, stomach, lung, and spleen.

\section{Discussion}

The basic structure of the NLR family is mainly composed of $\mathrm{N}$ terminal death effector domain(DED), C terminal LRRS, and central NBD and oligomerization domain(Lamkanfi and Kanneganti 2012, Motyan et al. 2013). The NLRC5 is the receptor protein of the currently highest molecular weight. The NLRC5 had an evident regulatory effect on producing the RLR-IFN signal pathway and its effector molecule type I IFN in many types of human and mice cells. The NLRC5 also plays an important role in inflammasome formation. As regards the important role of the NLRC5 protein in the innate immune process, providing an effective treatment target for improving immunity from diseases related to microbial infection and immune inflammation is possible. However, the NLRC5 function in the animal body and its effect mechanism participating in immune regulation are still controversial(Neerincx et al. 2013) and require further research. Studies on the NLRC5 gene in pigs have not been reported yet. Existing studies indicate that pigs are more superior experimental animal models than mice. Therefore, studying the relevant effects of the NLRC5 gene in pigs possesses certain reference meaning for the further exploration of its effects on humans. It also provides a new research idea on pig disease prevention and control. Therefore, cloning and analyzing the NLRC5 transcript sequence in pigs can provide a sequence basis and theoretical foundation for further study of NLRC5 effects.

In this study, we cloned the NLRC5 transcript in pigs and used bioinformatics software to analyze the obtained sequences. The results show that the total length of the pig NLRC5 gene cDNA is $6638 \mathrm{bp}$. The gene open reading frame is $5538 \mathrm{bp}$ and encoded a total of 1846 amino acids. The prediction result of the 
hydrophilicity, hydrophobicity, flexibility, and antigenicity of the NLRC5 mRNA-encoding products indicates that the protein encoded by this gene is mainly of hydrophilic property. The antigenic epitope is concentrated on the 5' terminal and the central domain, which can be inferred as the enrichment region of the antigen sites. The analysis of the structure of the NLRC5 mRNA-encoding products shows that the pig NLRC5 possesses the NBD and 20 LRRs. The amount of LRRs is less than that of the NLRC5 gene in the human and mouse. This study analyzed the 5' terminal structural domain of the NLRC5 with several types of software, but did not find the typical CARD or pyrin domain (PYD) of the NLR family. This result is consistent with those of the human and mouse analysis in existing reports (Meissner et al. 2012, Motyan et al. 2013), which can be used to infer that the $\mathrm{N}$ terminal of the NLRC5 has a new effector domain without evident homology with the CARD or PYD in the NLR family. This finding requires further experiments for verification.

The homology analysis results indicate that in comparing the 12 species' pig NLRC5, the NLRC5 transcript sequence is of the highest homology with that of cattle and sheep. The homology in the human, rabbit, horse, wolf, cat, macaque, and chimpanzee is around $80 \%$. The lowest homology is found in the chicken and channel catfish. This result is consistent with that of the genetic evolutionary tree, which indicates that the NLRC5 transcript is of high conservativeness in the long evolution, especially among mammals. This transcript possesses significant physiologic functions and has similar biological functions in different species. Interestingly, the study also found that the homology of the pig NLRC5 transcript with that of the human reaches $78.9 \%$, while that of the mouse to human is $74.0 \%$. This finding further proves that the pig is a more superior experimental animal model than the mouse.

Current bodies of research have mainly focused on the NLRC5 gene expression in immune tissues (Kuenzel et al. 2010, Neerincx et al. 2010, Meissner et al. 2012), whereas this paper expands the range of tissues and not only immune tissues. Tissue expression analysis indicates that the NLRC5 mRNA in the pig is expressed in many tissues, including immune organs, such as lymph nodes and spleen with high expression. This finding is basically consistent with the situation of the human and mouse. Notably, high transcriptional levels are found in the tissues with mucosal surfaces, such as the intestines, colon, stomach, and lung. This result suggests that apart from general immunity, the NLRC5 also plays a vital part in partial immunity in mucosa.

For the first time, this study successfully cloned the NLRC5 transcript in the pig and analyzed the relevant sequence characteristics. This study provides a theoretical foundation for the subsequent study of the NLRC5 transcript functions in animals and its antibody preparation. This research also offers reference for an in-depth understanding of the action mechanism of the NLRC5 transcript in the pig as regards participation in the immune regulation and effective prevention and control of infectious pig diseases.

\section{Acknowledgement}

This research was supported by the Natural Science Foundation of China (NSFC) (31302074).

\section{References}

Benko S, Magalhaes JG, Philpott DJ, Girardin SE (2010) NLRC5 limits the activation of inflammatory pathways. J Immunol 185: 1681-1691.

Cui J, Zhu L, Xia X, Wang HY, Legras X, Hong J, Ji J, Shen $\mathrm{P}$, Zheng S, Chen ZJ, Wang RF (2010) NLRC5 negatively regulates the NF-kappaB and type I interferon signaling pathways. Cell 141: 483-496.

Davis BK, Roberts RA, Huang MT, Willingham SB, Conti BJ, Brickey WJ, Barker BR, Kwan M, Taxman DJ, Accavitti-Loper MA, Duncan JA, Ting JP (2011) Cutting edge: NLRC5-dependent activation of the inflammasome. J Immunol 186: 1333-1337.

Kanneganti TD, Lamkanfi M, Nunez G (2007) Intracellular NOD-like receptors in host defense and disease. Immunity 27: 549-559.

Kumar H, Kawai T, Akira S (2009) Pathogen recognition in the innate immune response. Biochem J 420: 1-16.

Kuenzel S, Till A, Winkler M, Hasler R, Lipinski S, Jung S, Grotzinger J, Fickenscher H, Schreiber S, Rosenstiel $P$ (2010) The nucleotide-binding oligomerization domain-like receptor NLRC5 is involved in IFN-dependent antiviral immune responses. J Immunol 184: 1990-2000.

Kudlicka J, Mlcek M, Belohlavek J, Hala P, Lacko S, Janak D, Havranek S, Malik J, Janota T, Ostadal P, Neuzil P, Kittnar O (2015) Inducibility of ventricular fibrillation during mild therapeutic hypothermia: electrophysiological study in a swine model. J Transl Med 13: 72.

Lamkanfi M, Kanneganti TD (2012) Regulation of immune pathways by the NOD-like receptor NLRC5. Immunobiology 217: 13-16.

Meissner TB, Li A, Biswas A, Lee KH, Liu YJ, Bayir E, Iliopoulos D, van den Elsen PJ, Kobayashi KS (2010) NLR family member NLRC5 is a transcriptional regulator of MHC class I genes. Proc Natl Acad Sci USA 107: 13794-13799.

Meissner TB, Li A, Kobayashi KS (2012) NLRC5: a newly discovered MHC class I transactivator (CITA). Microbes Infect 14: 477-484.

Motyan JA, Bagossi P, Benko S, Tozser J (2013) A molecular model of the full-length human NOD-like receptor family CARD domain containing 5 (NLRC5) protein. BMC Bioinformatics 14: 275. 
Neerincx A, Lautz K, Menning M, Kremmer E, Zigrino P, Hosel M, Buning H, Schwarzenbacher R, Kufer TA (2010) A role for the human nucleotide-binding domain, leucine-rich repeat-containing family member NLRC5 in antiviral responses. J Biol Chem 285: 26223-26232.

Neerincx A, Castro W, Guarda G, Kufer TA (2013) NLRC5, at the Heart of Antigen Presentation. Front Immunol 4: 397.

Neerincx A, Jakobshagen K, Utermohlen O, Buning H, Steimle V, Kufer TA (2014) The N-terminal domain of NLRC5 confers transcriptional activity for MHC class I and II gene expression. J Immunol 193: 3090-3100.
Ranjan P, Singh N, Kumar A, Neerincx A, Kremmer E, Cao W, Davis WG, Katz JM, Gangappa S, Lin R, Kufer TA, Sambhara S (2015) NLRC5 interacts with RIG-I to induce a robust antiviral response against influenza virus infection. Eur J Immunol 45: 758-772.

Yao Y, Wang Y, Chen F, Huang Y, Zhu S, Leng Q, Wang H, Shi Y, Qian Y (2012) NLRC5 regulates MHC class I antigen presentation in host defense against intracellular pathogens. Cell Res 22: 836-847.

Zhao Y, Shao F (2012) NLRC5: a NOD-like receptor protein with many faces in immune regulation. Cell Res 22: 1099-1101. 